\title{
A Cultural Governance Coalition in Regeneration. A Case Study of Historical Quanzhou City
}

\author{
Shuxiang Cai \\ Quanzhou Normal University, College of Fine Art and Design, China \\ susiechoi@hotmail.com
}

\begin{abstract}
Compared with the gradual and long exploration processes typical of European and American countries, China experienced a period marked by extremely high-speed modernisation and urbanisation, following the Land Reform. This is exemplified by a great number of urban reconstruction projects which have changed the traditional fabric of most cities. Yet, following the trend of cultural consumption since the late 1990s, numerous integrated restoration projects for historic districts were implemented to promote tourism as a promising industry to sustain economic growth. As a consequence of growth-oriented urban entrepreneurship, public spaces in these historic urban areas have also been perceptibly privatised. To a large extent, the capital and the authority of the local government directs the future prospect of the historic urban landscape in Chinese cities. On the other hand, development-oriented urban construction stimulates a rise in awareness of the need for protection strategies to conserve historic urban fabric. On a global scale, the public sector has begun to introspect on urban governance under the spirit of entrepreneurship. The urban renewal has now been extended to urban regeneration and the previous public-private partnership has been substituted with a multi-sectoral cooperative model. In recent years, the Chinese central government has proposed the core concept of "Seeing people, Seeing things, Seeing life", which is re-orientated towards historic-city regeneration as a way of promoting "Micro-renewal and Micro-disturbance". Among such activities, the use of exhibitions as a strategy for simultaneous spatial transformation and activation has gradually formed a common path, encouraging many cities to regenerate historic urban areas. This article is based on this reorientation, taking Quanzhou as an example, making a critical observation on the new form of public space it has produced, and digs into the operational mechanism behind it as well as the possibility for publicness.
\end{abstract}

Keywords: historic city, regeneration, multi-sectoral cooperation, publicness

To cite this article:

Cai, S. (2019), A Cultural Governance Coalition in Regeneration. A Case Study of Historical Quanzhou City. The Journal of Public Space, 4(2), I45-I64, DOI I0.3289I/jps.v4i2.I 207

This article has been double blind peer reviewed and accepted for publication in The Journal of Public Space.

This work is licensed under a Creative Commons Attribution - Non Commercial 4.0 International License https://creativecommons.org/licenses/by-nc/4.0/ 


\section{Introduction}

The rapid development of China over the past 30 years has attracted the attention of the whole world. At the same time, the urban landscape has undergone earth-shaking changes. Development-oriented urbanisation has become the major appeal under the impact of modernisation, which has contributed to a "demolition economics" with unique Chinese characteristics (Yang, 2006). A large number of old cities have been demolished and rebuilt, transformed into high-end central business districts (CBD), modern residential areas, fashionable commercial streets, and even urban complexes.

The huge volume of the project erased the original urban fabric as well as social relations. On the other hand, parts of the remaining historic city areas were incarnated into tourist destinations as historic and cultural blocks, while some were lucky enough to have their original appearance preserved. However, the project failed to tackle problems such as vulnerable infrastructure facilities and ageing blocks.

Post World War II, European and American countries gradually explored the conservation and regeneration modes of intervening in historic urban areas, and each stage had its own distinct characteristics (Tallon, 20I3). However, China's rapid development compressed this process. Various types of regeneration patterns are occurring in parallel. The imitation of cases, learning from experience and the transplantation of policies - to some extent - assimilated the process of the regeneration of historic cities in China to the Western formula. By means of borrowing, the pace of space production can thus keep up with the pace of development, providing an ideal image and lifestyle of 'modern cities' for local politicians, investors and the public - as they are imagined in a quick and effective manner. In addition, the so-called local characteristics were integrated so as to meet the emerging needs expressed by cultural consumption and to establish uniqueness under the trend of globalisation and resulting homogeneity. In addition to borrowing these characteristics, the public-private partnership, which occupied the mainstream paradigm in urban regeneration in the West during the 1980s and 1990s has also been adopted. Similar public problems that originally accompanied this entrepreneurship can now also be witnessed in China. The difference, as Harvey (2005:25) said, is that China's reform and opening up, which happened almost simultaneously along with policies stimulating an increasing freemarket in the United Kingdom of Great Britain and Northern Ireland and the United States of America is a different kind which hybridises what he calls 'neo-liberalism' with authoritative centralised control. Therefore, whether in terms of implementation or effectiveness, its strength and breadth has outdistanced the previous experience of the West, and as such is connected with China's political and economic system in an inseparable way.

As a result of over-restoration or over-exploitation, irreparable and destructive changes - masked as protective measures - have been made to many historic urban areas in China, causing a lot of criticism and introspection. Now, the central government has put forward the core concept of "Seeing people, Seeing things, Seeing life", making "Microrenewal and Micro-disturbance" a new guideline for future conservation efforts. Globally speaking, entrepreneurial urban governance has shifted, placing its emphasis on a multi-sectoral cooperation model formed by uniting the third sector, not just the public and private sectors. How should China's old cities cope with the challenges 
brought forward by the shift in awareness of the times as well as the re-orientation of policy?

\section{Review of the Context}

\section{I Western Experience of Old City Regeneration}

Since the end of World War II, inner cities in the West have been undergoing several stages of modification, namely: reconstruction, revitalisation, renewal, redevelopment and regeneration (Roberts \& Sykes, 1999: 17). The context behind these processes is a series of inner-city crises and economic problems brought about by urban expansion and de-industrialisation. The promulgation of the 1977 White Paper 'Policy for the Inner Cities' meant that the government of United Kingdom of Great Britain and Northern Ireland recognised that it could not rely on its own strength alone to solve huge urban problems (Tallon, 2013:39), so it opened the door of urban governance based on an entrepreneurial attitude. The government's attitude towards inner cities changed from managers-lead planning to an urban governance based on public-private partnerships, thus shifting policies. Local governments attract investors to return to cities by means of subsidies grants, tax exemptions and deregulation of planning control, encouraging the private sector to redevelop the decaying historic cities (Healey et al., 1992). Therefore, in terms of urban development, the roles these two entities play have changed, as more and more private capital impacts on the operation of urban space production. The partnership between the public and private sector not only alleviates the government's financial burden, but also reshapes the decaying image of the historic city and promotes the redevelopment of the local economy. The urban renewal model including publicprivate partnerships has been based on market involvement, hence entrepreneurship. It have been widely disseminated and replicated around the world, as the approach to revitalise inner cities.

However, after the real-estate-oriented urban renewal took up a dominant position, local governments and communities continued to be marginalised (Turok, 1992).

Ultimately, despite the original intention of solving urban decay, this mode of urban renewal not only fails to improve conditions in the poorest areas (Herbert, 2000), but also causes further deterioration of social and spatial inequality. Smith (2002) pointed out that under neo-liberalism, local governments became agents of the market, not regulators. The gentrification, which meant unplanned, fragmented and spontaneous behaviour from the middle class in the 1960s, has been widely used as an important urban strategy in cities of all sizes around the world since the 1980s. In the name of public-private partnership, the privatisation of the inner-city land was systematically strengthened.

That is to say, that in the traditional society, "public space" which means "common property", has been continuously delineated as private property as a result of this process. Moreover, this false "publicness" was subsequently exposed and thus criticised by many scholars. Habermas refers to those pacified and privately-owned public spaces as the "colonization" of the public sphere (Zou, 20I5: 179), an action which is now percolating into the mainstream in society. Ubiquitous surveillance reveals the exclusiveness of these public spaces which contributes to the detrimental effects of the privatisation or commercialisation of "public space" elements, as exemplified by the 
chaos ensuing in the form of vagabond demonstrations and poverty: all in the name of security and purification (Zukin, 1996). In these spaces, the street ballet in daily life as emphasised by Jane Jacobs (1992) is no longer the main repertoire on the city stage. On the contrary, the state and enterprises have obtained right to express culture to the public. Under capital and power, "public space is merely a side-line seat to watch the spectacular corporate wonders that have been carefully monitored” (Bolton, 1989). Apart from the variation in property rights, another focus is on the reproduction of meaning in public space. Habermas (1989) focused on the important concept of the public sphere. He regards public space inhabited by the middle class, such as the salon, cafe and club - which were born from a market economy - as social places where public affairs can be reasonably debated and the critical power of liberalism and individualism can be brought into play. Its spatial significance guides the vision of democratic politics and explores the possibility of public participation. Unfortunately, although modern urban planning preserves a large number of public spaces, most of them are cold and hollow. Public spaces have faded and become nothing but empty shells (Sennett, 2017). It can be said that under the spirit of entrepreneurship, public space is not only commercialised and privatised, but also flattened and simplified on a cultural level. At its core, entrepreneurial orientation in politics blocks the potential for stimulating social action.

Generally speaking, the overall effect of urban renewal that took place in the 1980s was considered to be negative (Atkinson \& Moon, 1994). In the face of controversy, government policy began to be gradually restructured in the 1990s. Urban regeneration, which shifts from a single goal of economic growth to a more multi-dimensional perspective, is a "comprehensive and integrated vision and action which leads to the resolution of urban problems and which seeks to bring about a lasting improvement in the economic, physical, social and environmental condition of an area that has been subject to change" (Roberts, 2000: 17). Therefore, the corresponding urban policy should not only pay attention to the decline of the physical environment in the inner city, but also emphasise the activation of regional industrial vitality and soft functions, while focusing on the social and economic diversity factors that can benefit existing communities (CLG, 2008; IPF, 2009) and the fundamental principles of sustainable development. The publicness has also become more open and inclusive, emphasising diversity and differences. Fraser (1990) criticised Habermas' ideal of the public sphere as it represents the dominant value held by a white, male and middle class, and revised it on the basis of advocating a more pluralistic public sphere. Similarly, Carter et al. (1993) also pointed out Habermas' over-idealisation and homogenisation of the bourgeois public sphere, and proposed the a heterogeneous public space in the city as a place for debate, open to different-groups with different orientations.

Various local communities and residents who were previously excluded began to attract a significant amount of attention, and multi-sectoral cooperation began to emerge (Tallon, 20I3: 68). Community participation, advocacy planning and other methods are now integrated into urban governance. There are also many active civil society groups that try to regain dominance over urban public space from the bottom up, through various urban actions (Kung, 2016). 


\subsection{The Encounter between Entrepreneurship and Chinese Historic Cities}

As Harvey (200I:347) puts it, the entrepreneurial stance of promoting local government economic development activities seems to be a general consensus, across national boundaries, and even across political parties and ideological boundaries. Indeed, whether in the Europe and North America or in China, it is a common experience for almost all cities under globalisation to privatise previously public or indistinct publicprivate space into space controlled by capital, and to include it in the consumption of commodities by means of public-private partnerships.

China's reform and opening up in the 1970s and the Land Reform in the 1980s reconstructed the relationship between the state, the local government and capital through a series of political and economic adjustments. The policy of "decentralisation and concession of interests" as part of the reform and opening-up has further reconstructed the fiscal distribution between central and local governments, endowing local governments with greater autonomy. This means that local governments need to shoulder the burden brought on by local economic development. In the 1980s, the reform of public ownership of land divested the right to use land from the ownership of land, and defined the indisputable property of land as "urban land belongs to the state". The supreme power of ownership of land enables local governments to obtain financial revenue through the transfer of land as a main source of income. Through this approach, the channel for local governments to develop the local economy is unclogged, which stimulates the initiative of urban construction and promotes the process of land commercialisation.

Under the basic framework reform of the domestic development mode and the influence of globalisation, cities have turned to entrepreneurial governance and advocated the orientation towards "growth first" (He\&Wu, 2009), which has triggered the rapid change in China's urban landscape. Local governments play a decisive role in determining the future of local appearance; they are embedded in the large national system and power framework, but they are also the specific promoters of the state-led strategy; at the same time, they can obtain the legitimacy of urban transformation and development as agents, inherit state power, and obtain control over urban land by administrative force; and finally, they can obtain investment by using land as a medium to recruit distributors as co-operators. Thus, local governments are at the core of the interrelationship between the central government, the individual and the market (Shi, 20I5:127).

In the process of urbanisation, urban renewal has become the main driving force behind local economic development. The results of spatial practice carried out by public-private partnerships have rapidly emerged in all cities throughout China. As a result, conflicts and tensions between the process of urban renewal and historic cities in China are increasing. The commercialisation of space is the key factor. One of the most frequently discussed models is known as “Old City Reconstruction (旧城改造)” (Zhao, 2012; Shi, 20I5), in which historic neighbourhoods are demolished as a kind of slum clearance, and is complementary to the real-estate boom which occurred in the 1990s. By creating a discourse surrounding historic urban fabric which presents intervention as a simple "Reconstruction of Dilapidated Buildings", the historic city is categorised as an impoverished place in respect to the "modern city". Meanwhile, traditional life is 
posited as the antithesis of modernity, and is therefore taken at face value as a justified excuse to empty land and relocate residents.

However, in order to maximise the value of land, local governments cooperate with developers to demolish large numbers of old buildings and replace them with commercial housing or other modern functional sites. Despite the fact that regulatory control provisions for the protection of historic cities are in place, these provisions are still ignored or circumvented by many political operations. For example, regulations which ought to control volume ratio and enforce the height limit are being broken constantly and the landscape comprising historic urban areas has been nibbled at and guzzled. Driven by the booming economy, destruction of the historical fabric has occurred at an unprecedented pace around 1999 (Whitehand and Gu, 2007: 650). In the process of city reconstruction for Beijing, alleys disappeared at a rate about 600 per year at that time (Huang, 2004: 124). When compared with the situation in 1949, the total area of traditional houses within the old city has reduced by more than half in scale (Dong, 2006: 195-196). The boundary of traditional public space in the city is produced during the long-term negotiation process that is neighbourhood life, which being both vague and dynamic, endows itself with urban vitality through various elastic uses of space (see Fig. I). Tradition has been replaced by a new model, transformed into a welldefined access-controlled community, commercial plots and office space, which divides the original public space. The discourse surrounding safety and modes of property management etc., under the pretext of modern life, rationalised its existence and thus gained public recognition.

In addition to real estate development, another major model is the restoration of historic blocks (Chen, Zhang, 2010; Su, 2015). China began to evaluate historic and cultural cities in 1982, but for a long time the protection of historic blocks was not taken seriously by local governments. On the one hand, every year, the government at all levels allocates extremely limited funds to protection - which is utterly inadequate for protecting historic districts; on the other hand, the protection of historic districts seems to restrict the development of urbanisation and is even regarded as a stumbling block to the growth of the local economy (Zhao, 2002). However, with the rise of cultural consumption, historic blocks have brought considerable benefits to local tourism economies and have become an important part of securing local economic income. Marketing urban heritage has proven to be an effective policy in helping cities succeed in the face of regional competition and economic restructuring (Britton, 1991). Local governments began to be obsessed with cultural construction projects for various historic blocks. Nowadays, portions of urban fabric that have been nominated as "Historic and Cultural Blocks" at a national, provincial and local level, are beyond count. Many of them serve tourism consumption in a semi-commercial or even completely commercial mode.

For example, the "Shanghai Xintiandi" project, which won many international architecture and culture awards, is under the banner of the protection of historic blocks, but on closer inspection it appears in the form of historic real estate. Essentially, developers do not focus on the cultural value of the building itself, but create a delicate historical atmosphere for the purposes of consumption. Therefore, a large number of architectural details and symbols are extracted from their original locations and reassembled, a reminiscent practice of selling high-quality reproductions of the past in a 
fine manner, that not everyone can afford to buy. Even the so-called orthodox local lifestyle has been packaged as a commodity. This practice has been imitated by many cities, such as in "Wide and Narrow Lanes", "West Lake World" and other large-scale integrated historic block redevelopments (Kwok, 20I I). A large number of historic spaces have been commercialised and then privatised in the name of preserving cultural heritage. These spaces have become symbolic spaces, which differ from spaces used by the general public as part of daily life. It may be like a Chinese-style "Disneyland" — it may create a theme park of "cultural and historic landmarks", and at the same time it exposes the government's achievements in political leadership in terms of: protecting historic cities, accelerating local public cultural-construction, promoting local economic growth, and satisfying social consumption needs and so on. (see Figure 2). Its prevalence is no less than that of historic-city reconstruction, and it is still an important strategy for the development of many historic cities in China. However, this so-called "protection" conceals the fact that the capital is eating away original neighbourhood communities and supplanting local life. In many cases, native residents have to move away due to rising rents, soaring prices, or a lot of commerce. "The protection of the historic city" has been turned into a camouflage for commercial development, and the legitimisation of that protection has become a means of cleaning up the space desired.

Post-commercialisation, many public spaces which were originally shared by residents living in neighbouring streets and lanes have been transformed into privileged spaces for proprietors, or spaces for commercial operations in the name of the protection of historic blocks. Consumption serves as the basis for access admission. Capital and power are making their voices heard in the development of these historic cities. The logic in local daily life has been replaced by the logic of capital operation, transformed into privatised space to achieve maximum economic benefits. The public space has been distorted during the process of privatisation.
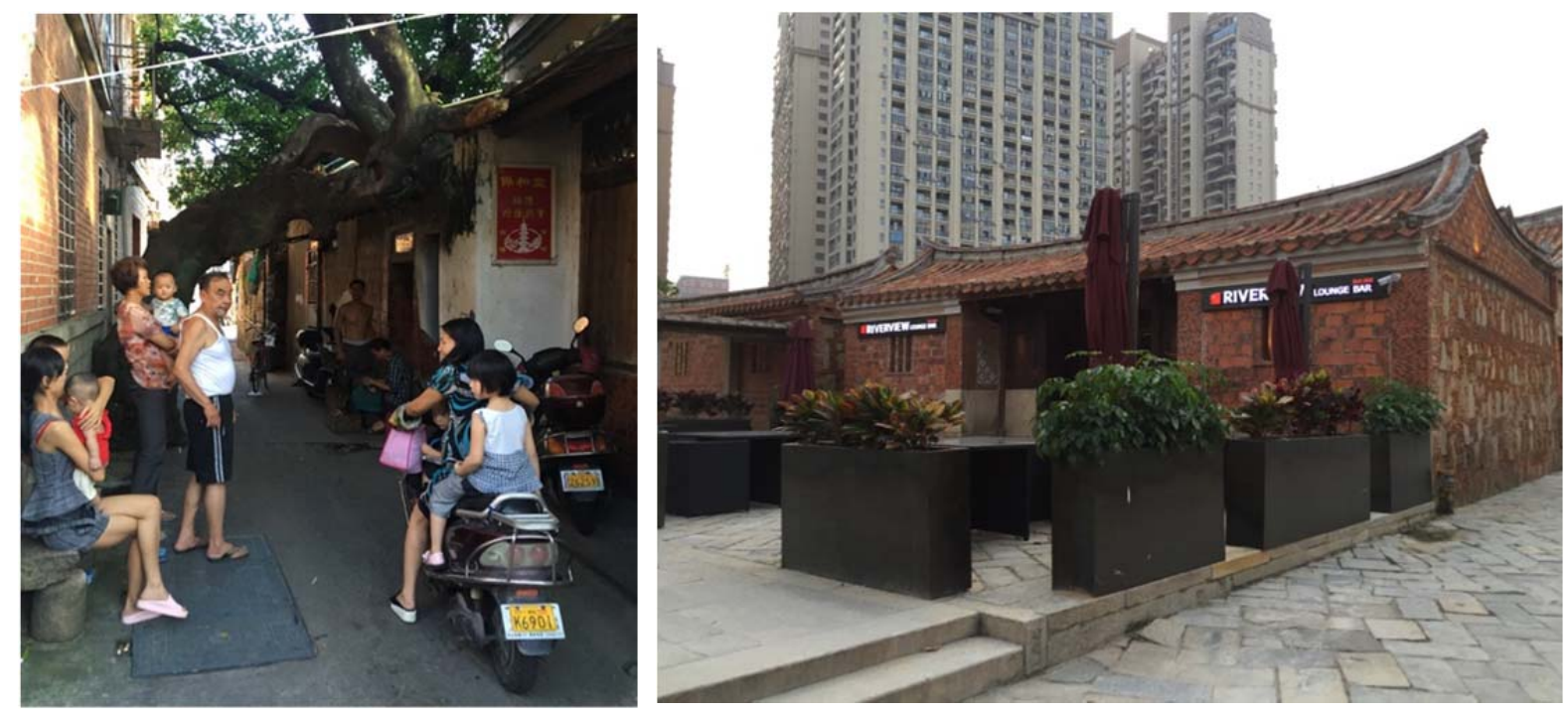

Figure I (left). Public space in the neighbourhood of Quanzhou Historic City. Figure 2 (right). Public space in the traditional cultural district of Wudian, Jinjiang. 


\section{Conservation Practice under the New Concept and the New System: A Case Study of the Historic City of Quanzhou.}

If the rapid development following China's reform, opening up and land reform can be considered to comprise the first stage of China's urban renewal, then it can be clearly observed that during this period a large number of historic urban areas were exploited and commercially operated in a stereotypical manner. Public space now serves as a space under capital control, reminiscent of Western theories and lived-experience. Along with the global trend of reflection on the privatisation of public space and the enhancement of public awareness of conservation, the development-oriented publicprivate partnership model for historic urban areas has been questioned, criticised and rejected, and the local governance crisis concerning the redevelopment of historic city areas has been brought to the surface.

In recent years, another concept and trend has gradually revealed itself. Under the central guidelines of "Seeing People, Seeing Things, Seeing Life", all governmental activities at the local level began to adopt this as the core concept for the regeneration of historic city areas; in addition to substituting an earlier model of an overall restoration in favour of proposing the paradigm of "Micro-renewal and Microdisturbance" for conservation strategy - with a view to building a sustainable future for urban development. In China, public participation has been motivated by these topdown policies, while such participation was carried out spontaneously in Western countries. Under the guidance and encouragement of local governments, the private sector also concerns itself with a parallel development of non-profit causes. Considering the shift in conservation philosophy and practice and the circumstances created by the particularity of the one-party dictatorship in addition to state-led political power - is there an opportunity to balance or even reverse the ingrained mode of historic-city redevelopment which has usually been excessively capitalised? Are there any opportunities to stimulate the vitality of cultures and the re-emergence of publicness? Quanzhou has also experienced a new round of attempts with the new concept. During this period, the author conducted a three-year field survey by means of participatory observation. Quanzhou was one of the first cities to be listed as a "National Famous Historic and Cultural City" in 1982. The outline of the ancient city can still be seen clearly today (see Figure 3). However, between the early 1990s and the early 2000s, Quanzhou was not able to escape the fate of historic-city reconstruction. A large area of the old city has been renewed. Only in 2006 did local governments adopt the "gradual, micro-circulatory" principle. The West Street historic district is defined as the "Core Protection Area" for its location is on the periphery of the Kaiyuan Temple, a national cultural protection unit. It is now the only area which has been preserved and as such has remained relatively unscathed. However, the funds allocated by local governments for the purposes of protection and maintenance are extremely limited, a mere 400,000 RMB a year. The new protection system had high hopes that building owners could spontaneously repair the buildings in the protected area, which mainly encompasses private commercial and residential buildings. But the fact is that the strict and complex approval process and the low volume-rate restoration requirements have kept many property owners away. According to the statistics available from the 'Quanzhou Historic City Protection and the Remediation Planning Specification' (2007: 8) issued by Quanzhou Planning Bureau commissioned by Quanzhou municipal 
government, in the year 2000 the number of first-class preserved buildings was documented at 126, this figure dropped to 81 by the year of $2006-45$ buildings disappeared over a period of only six years. Common problems in old cities such as: ageing buildings which might collapse at any time, offshore migration of native residents, and rent decline and industrial stagnation are posing a growing threat. Although over the past ten years the public sector has been trying to generate various schemes to promote conservation, local governments must contend with a chorus of conflicting voices which renders making strategic decisions difficult. How to regenerate historic urban areas is a long-standing problem that has long plagued local governments.
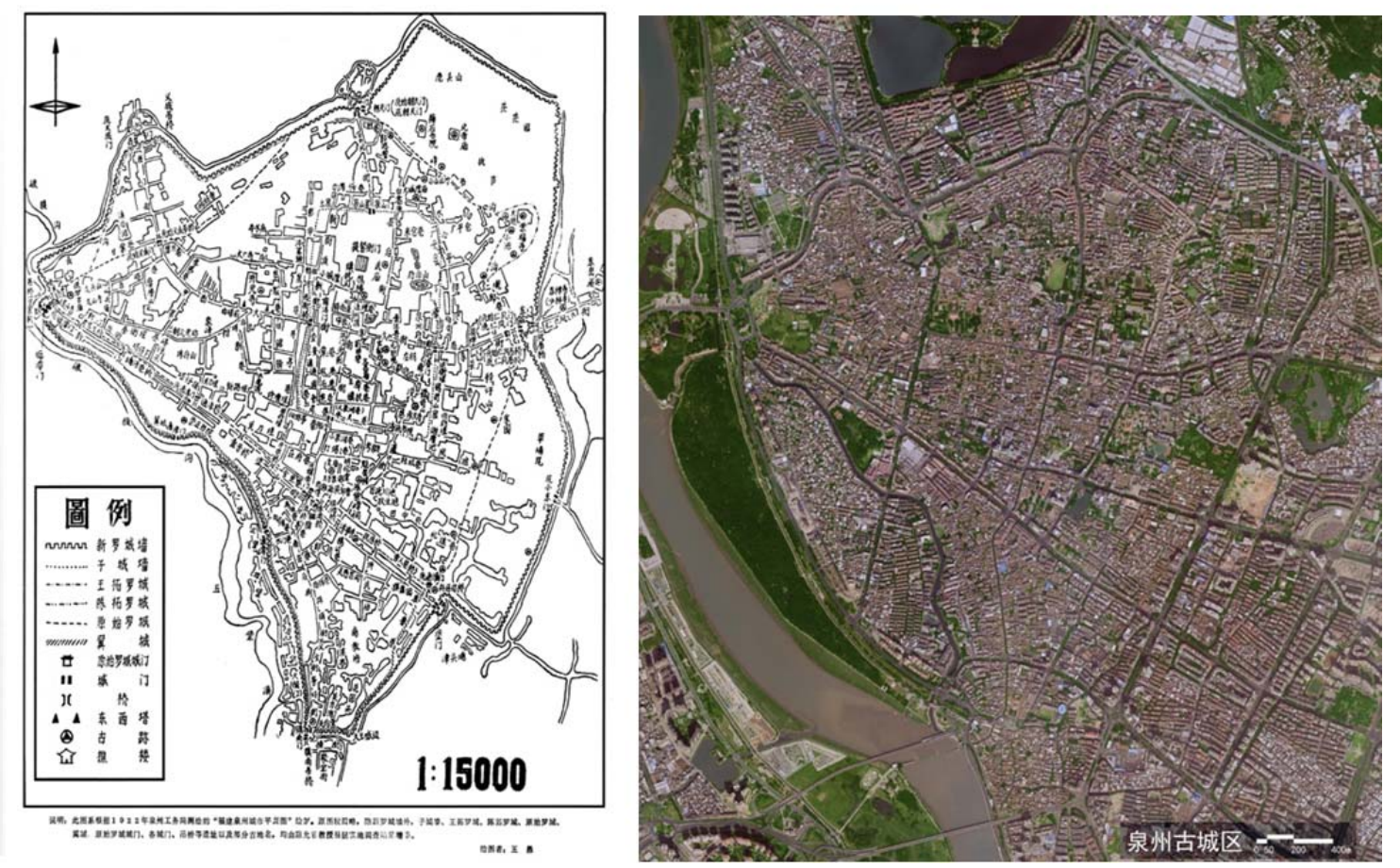

Figure 3. Left: A Mapping Survey of Quanzhou in 1922.

Right: An Aerial Map of Quanzhou in 2016.

Since 2016, Quanzhou has held a series of exhibitions entitled "Soundless Lubrication ( 润物无声)" as one of the cultural strategies for space activation. Unlike regular exhibitions which are commonly held in large art centres, the understated nature of the Soundless Lubrication exhibition reflects its name. It carries the hope of lubricating everything in a silent manner, which in practice means that it doesn't intervene in the city with a one-time direct action but instead appears in small, informal ways where it is sprinkled around in numerous micro-spaces in streets and alleys in the historic city: integrating itself into these areas, and thus gradually activating historic city areas. The use of an exhibition as a regeneration strategy may not be new, but from the perspective of its underlying mechanism, the exhibition for historic Quanzhou has the following special attributes which are worth exploring. 


\section{I Coalition restructuring}

In the past, it was local planning bureaus, planning institutes and other professional departments which represented the public sector, and acted as the major governing units for the protection of historic cities. These units were mainly focused on materialoriented protection strategies. Although the units are often regarded as professionally competent units, authorised to protect historic fabric, in reality they have very limited access to human and financial resources, power or scope for impact at administrative decision-making levels. Wading through the multiple layers necessary to gain approval so as to obtain protection funds is always a long process, even if they set up a specific channel designed for submitting their projects for approval separately. This leads to difficulties in the implementation of protection strategies in historic cities and in turn, conflicts in development-oriented local governance. Based on the experience gained in past decades, the conservation surrounding historic cities around the world has been constantly updated, and has made people aware of the fact that protection should not be too dependent on pre-modern traditions or be restricted to a certain single historical level. According to the Recommendation on the Historic Urban Landscape promulgated by UNESCO in 20I I, moving forward, the purpose of historic urban landscapes should not only be rooted in their protection, but should also be about maintaining and improving the overall living environment for human beings. That is to say, conservation should also be integrated into urban development strategy, thereby establishing a broader and multi-level urban development context which considers the city's habitability and the sustainability of all of its aspects, including the role of different stakeholders (Kang, 20I2). Therefore, the conservation and activation of historic cities must face the problem of cross-domain cooperation directly. Compared to the past, local governments are increasingly more sensitive to the social impact and are more cautious in seeking strategies to achieve a balance between protection and development. Triggered by many factors, the coalition related to the regeneration of the historic city of Quanzhou has been restructured.

In early 2016, Quanzhou established the "Quanzhou Historic City Conservation and Development Coordination Group", a provisional public organisation headed by the mayor: a move which aimed to bestow sufficient decision-making power on the new initiative. Formed by a range of offices and different working groups, the organisation includes a planning group, a cultural group, a policy group, an advocacy group and other various groups with different responsibilities pertaining to daily operations. By borrowing outstanding talents from various government departments and institutions, the government devotes time and significant efforts to bringing people from different fields together and encouraging collaboration - including relevant units which had been working for the protection of historic cities over a long period of time. At the same time, "Quanzhou Historic City Development Co., Ltd. is responsible for the protection and development of the daily work"I - which lays out the role of private sector in public-private partnerships. In fact, Quanzhou Historic City Development Co., Ltd. is a

I The website of Quanzhou Municipal People's Government (2016), "Notice of the Office of Quanzhou Municipal People's Government on the Establishment of the Coordination Group for the Protection and Development of Quanzhou Historic Cities" is : http://www.fjqz.gov.cn/zfb/xgk/zfxgkzl/zfxgkml/srmzfxgkml/jgsz/201602/t20160229_250507.htm. $(2017 / 08 / 21)$ 
subsidiary of a wholly state-owned enterprise. That is to say, that although in the past public-private partnerships usually referred to the coalition between local government and private capital, under the Chinese system, it is now possible to form a coalition between a local wholly state-owned company 2 and the local government. Put simply, the right and left hands of local governments are now working in collaboration (see Figure 4).

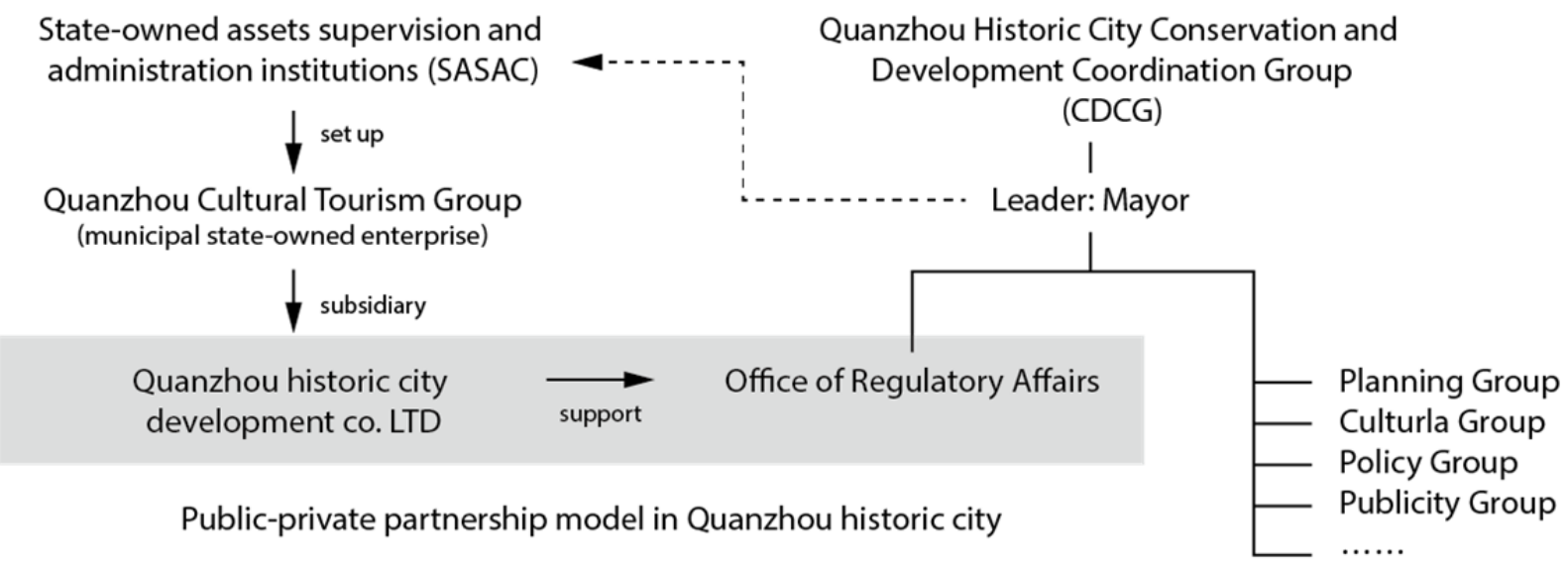

Figure 4. Diagram of the New Governance Structure for the Historic City of Quanzhou.

The problem of an inadequate protection fund that occurred under current allocation can thus be solved by establishing a state of cooperation between the local government and the company set up by the state-owned assets supervision (SASAC), in addition to administration institutions at the corresponding level. The regeneration of the historic city would then have government funding on its side to cover the corresponding expenses. The biggest difference here, when compared to former protection agencies, is that the coordination group and the Quanzhou Historic City Development Company are now connected in terms of decision-making power levels in the command hierarchy. Hence, difficulties and delays caused by the toilsome process of advancing past red tape could be averted. Such a partnership seems to imply a strong government-led situation and a centralised decision-making approach, and companies under the SASAC are still profit-oriented, but there are several limiting factors.

Firstly, the two guidelines, "Seeing people, Seeing things, Seeing life" and "Micro-renewal and Micro-disturbance" established by the central government, in addition to the general protection regulations for historic Quanzhou known as "gradual, microcirculatory", together serve to delimit the development framework of historic city regeneration. Meaning that the old model which favoured large-scale demolition and reconstruction is no longer imitated or duplicated.

2lt refers to the socialist enterprises owned by the people in China. It is a company that possesses and controls all or most of its assets. It was originally operated directly with the state and was called a stateowned enterprise. In the economic system reform, ownership and management rights began to separate, and the state did not participate in direct operations, so it was renamed as state-owned enterprises. 
Besides, setting up an organisational model in which the mayor is directly responsible for the acts of the local government, drives the local government to adopt a more cautious attitude in the protection and development of the historic city.

Thirdly, the new governance coalition includes planning and scheming companies, professional protection teams, local individual actors and so on. As a result, the promotion and implementation of any strategy need to be coordinated by various agencies. This reorganised coalition and working mode and others like it are intended to posit all fields indiscriminately and ensure that the voices of all parties involved are heard, so as to create a more direct and effective way of communicating as well as a more comprehensive view for regenerating the historic city.

Another difference is that in the past, public-private partnerships were mostly businessled agendas, aimed at obtaining short-term solid business gains rather than being concerned with social well-being. Harvey (200 I: 354) proposed in Spaces of Capital that urban entrepreneurialism - which typically relies on public-private partnerships focuses on opportunistic local construction for investment rather than improving conditions in specific areas as its immediate political and economic objectives.

Nowadays, this notion probably ought to be renewed. Speculative entrepreneurialism is no longer absolute. With the decline of the tide of urban renewal, and upon reflection, governance under the model of public-private partnerships has gradually turned towards a long-term sustainable development. In addition, private sector attitudes should be shifted from a speculative-oriented to an investment-oriented perspective and more enduring effective mechanisms should be taken into account to ensure the common growth of local groups.

\section{Temporary, Informal and Popular Participation}

Historic city reconstruction used to be actioned in one go after the decision to do so had been made, so as to maximise benefits-recovery through short-term construction. Therefore, it was basically impossible to revise the process of reconstruction midway. In the context of the restructuring of the governance coalition, the investment-oriented attitude shifts the target from a short-term-profit-oriented to a long-term-planningoriented process. Therefore, the exhibition was treated as a loose and temporary cultural project, which is also related to the long-term planning of local cultivation, and thus creates a new mechanism. Unlike the rigid construction projects of the past, the exhibition is defined as a soft regeneration mechanism, which is not only a kind of space production used to experimentally explore the local response to spatial practice, leading to gradual space revision as well as space adaption, but also a cultural strategy of reviving the historic city culture and activating historic city space - triggering more dialogue between different groups with its focus set on the reproduction of space. That is to say, the former is a micro-transformation of space itself, while the latter is a form of micro-disturbance by means of urban curation.

The main theme of the exhibition is to conserve the historic city and assemble social exhibitors. In particular, it does not specify the identity of the exhibitors or the content of the project. Instead, the applicants put forward their curatorial plan according to their own ideas. There will be periodical renewals of exhibitors, exhibition areas, and exhibition contents. Due to the temporary nature of the exhibition, it seems that the 
exhibition has not been formalised into a certain kind of governable behaviour, prying out a crack within which the bureaucratic approval process could be then skirted. Under the premise of such a mechanism, exhibitors can have more freedom to decide upon richer exhibition content: making it possible to accommodate differences and diversity. So far, the exhibition has attracted followers and purveyors of lacquer art, ceramic art, Nanyin, puppetry and other local traditional arts, in addition to young people who have a deep appreciation for local traditional culture in the form of wood carving, costume design, makeup and so on. Other sub-cultural groups take this chance to pledge their subjectivity in the historic city. These folksy organisations have also filmed local documentaries on the back of the event. The exhibitors present their relationships with the historic city from their own perspectives, through individual micro-narratives. These enthusiastic participants are willing to communicate with citizens and tourists during the exhibition, explain the exhibition content, share their experience of historic city life, and even initiate participatory activities. As a result, the exhibition has served as a medium to encourage public participation, but also a bridge to connect different groups of people as well as historic city spaces.

The micro-renewal of historic areas is implemented simultaneously in the name of the exhibition, and is subjected to public inspection. These spaces involve Dacuo (大厝) and foreign-style houses enshrined in deep streets and lanes, as well as pop-up spaces that appear in roadside shops and squares (see Figure 5,6 and 7). If the public responds well, those particular space transformations will be continued with support from the public sector and might even make the considerable shift from temporary usage to being part of long-term planning. However, space transformations that are disapproved of will later be restored or revised so as to relieve the conflict between the public sector and the people, on the grounds of the temporary nature of the exhibition. This leaves room for local voices on the issue of space transformation, so the daily life of local people can be taken into account in a real way when making space-transformation decisions. Although participatory design has not yet been achieved and the public voice is still a passive stimulus-response result, it does however reserve a modifiable flexibility from which people feel empowered to increase their concern for public affairs.

By implementing the exhibition as a regeneration strategy, the governance coalition hopes to deal with problems related to space in the historic city in a progressive manner, and give people confidence in the process of regeneration thereby triggering more actions pertaining to self-maintenance. At the same time, a platform for the public voice is being established to arouse people to pay attention to and recognise value in the historic city. In turn, this empowers grassroots movements by enhancing the sense of ownership people feel towards these places, thus attracting more and more people to participate in regeneration actions. This strategy faces the irrationality of the past protection mechanism, breaks away from the old administrative management structure, opens up new paths and structural relations, eases the tension between the public sector and the private sector, and stimulates local actors. The initiative has, to a certain extent, alleviated the crisis of the historic city redevelopment in terms of local governance issues. 

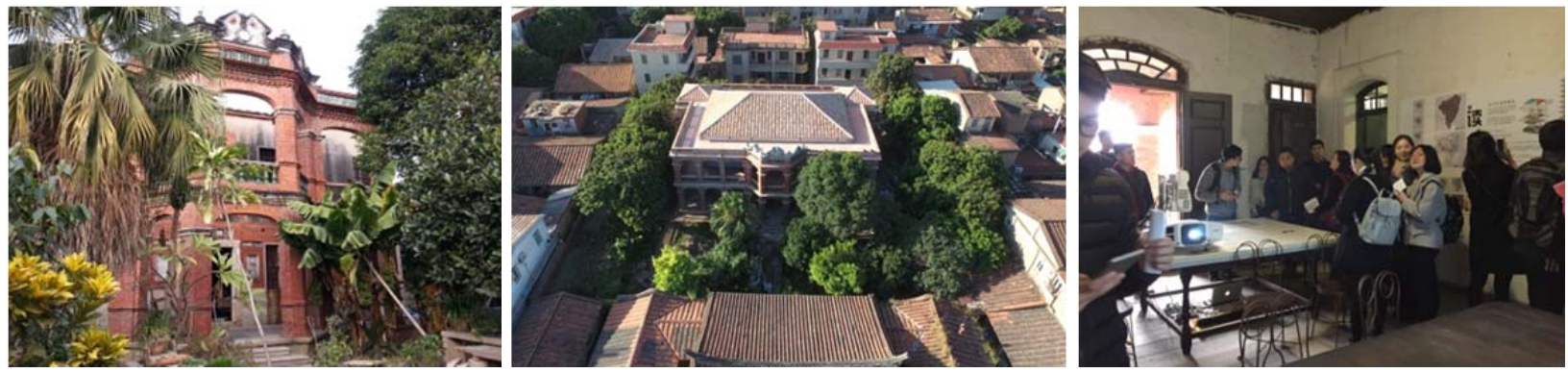

Figure 5. Before, after, and open exhibitions at II6 West Street.
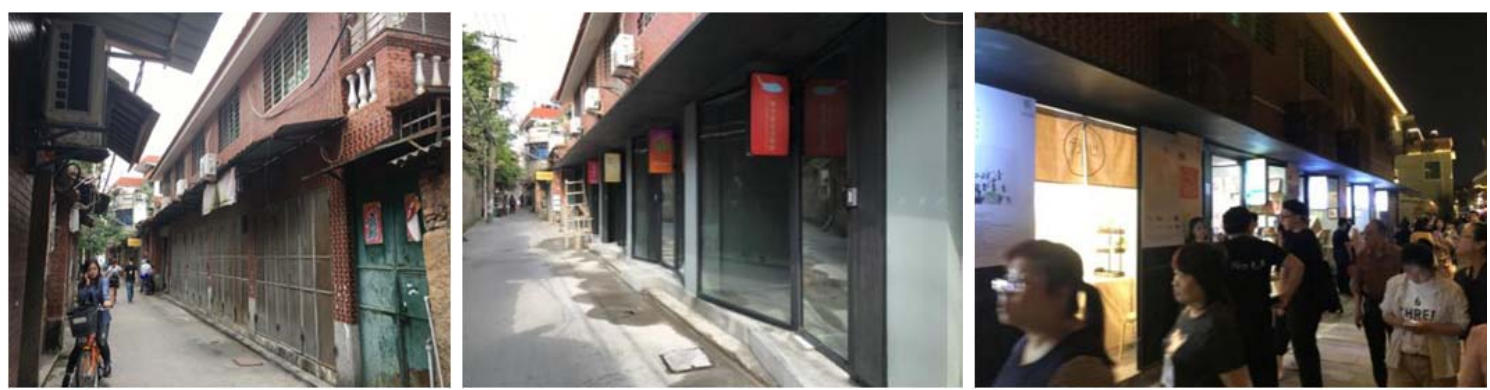

Figure 6. Before, after, and open exhibition of No. 22 Jinyu Lane.
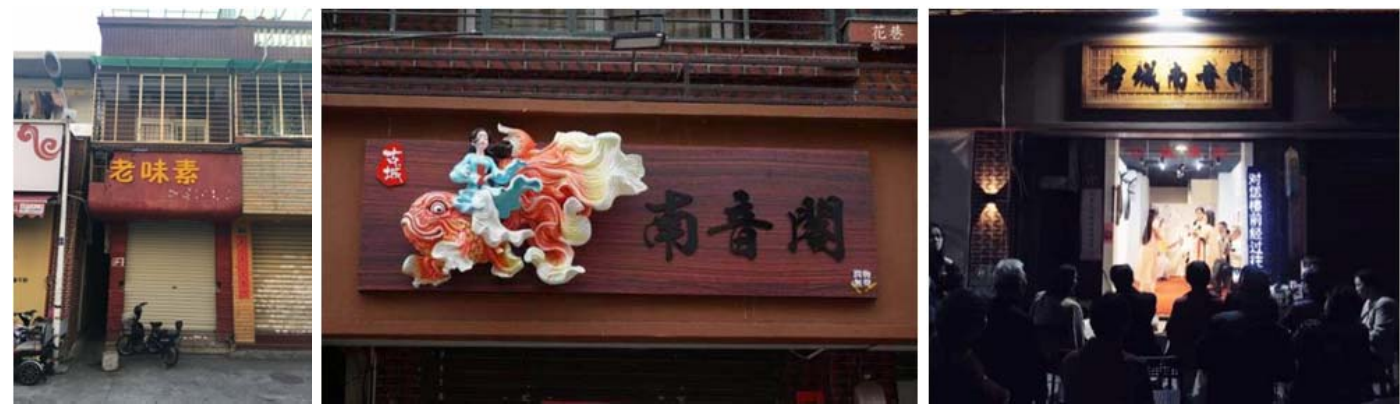

Figure 7. Before, after and open performance activities of the No. 37 Jinyu Lane.

\section{Reversal of Space and Publicness}

In European and American countries since the 1980s, government initiative and control have been being handed over to free markets and private capital, which has ultimately led to the privatisation of a large number of urban public spaces that triggered strong criticism and debates surrounding the notion of publicness. However, in the Chinese context, the regeneration of the historic city is somewhat different from the operational logic characteristic of the Western public-private partnership model. Regardless of the reconstruction of the historic city that pursued economic growth in previous decades, or the micro-renewal and micro-disturbance practices typical of the current urban management philosophy, "Seeing people, Seeing things, Seeing life", the government has always been in a dominant position (Zhang, 20I4). In recent years, throughout many cities in China, there have been more and more cases of historic city regeneration strategies founded upon exhibitions, such as Beijing Design Week, Shenzhen Hong Kong Biennale and Shanghai Urban Design Festival, to name a few. In all these cases, the 
government, enterprises, and the third sector jointly work together to operate historic city areas. Most of the large-scale events carried out which are wider in scope are based on cooperation between local governments and local state-owned enterprises, working in a collaborative left-hand-with-right-hand attitude. Local state-owned groups, as capital parties that cooperate with government policies and funds, not only need to make profits as their ultimate goal, but also need to constantly seek a balance between public interest and their own interests. The last part of the article will focus on this issue and re-explore the inherent contradictions in public space formed by the exhibition as event, in addition to the possibility of the formation of publicness under this cooperative mode of practice.

In the traditional urban space, the distinction between public and private life is not clear. It is often regarded as a vague boundary which is mutually infiltrated. In southern Fujian, the two traditional architectural types, the arcade and the front courtyard of Dacuo, are concrete manifestations of private space which has been put to public use. Therefore, public and private can be defined as relative concepts. In addition to the ownership of property rights, whether a space is public or private can also be classified according to who has the power to access the space, and the public or private nature of activities taking place in the space. That is to say, the definition of public space is the interlacing of property rights, access and activities, which varies depending on the situation (Wang, Shen \& Lin, 2009: 9). This is similar to the concept of "public" in Japan — what constitutes a public space is determined by the events which take place there. That is, a public activity determines the scope of space at a specific time, without a tangible, permanent boundary (Hidaka \& Tanaka, 200I).

In this sense, the public events created by the exhibition flip various micro-spaces in the historic city into a source that could be could be used with visible effect in the near future under this framework, shifting them from private to public, which reinvigorates and diversifies the public spaces in historical Quanzhou. But in fact, the reason for the emergence of these public spaces is that under the new cooperative structure, the government is to repair some old buildings in the historic city that have remained unused for a long period of time or which have even collapsed, in order to exchange the right to use them, thereby assisting Quanzhou Cultural Tourism Group, the stateowned company, in the storage of fixed assets. Although it is a progressive and yet piecemeal repair process, there is a set of overall planning guidelines which serve as a reference point. These represent a revision of the previous method of integral reconstruction or restoration which guided past interventions. After the restoration, the government and state-owned company then introduced cooperation from the third sector. On the one hand, they mobilised local resources as much as possible to jointly activate these spaces. On the other hand, they bestowed a higher profile on the historic city and promoted an increase in small capital injections. Although top-down centralised politics is often criticised, it is this supreme authority that has the power to mobilise enough resources financial, material, human or otherwise, and to formulate the necessary corresponding policies and regulations such as rent control, support for businesses, etc. This is rare in the Western context. Thus, the top-down model has the capacity to transform the logic of interest-oriented space production into the core concept of "Seeing people, Seeing things, Seeing life", guided by public opinion. Its concentration, universality and operational intensity - and the effects that can be 
produced in a short period of time - differ greatly from the modes of spontaneous or small-scale capital intervention.

However, exploring the driving forces behind these public spaces still seems to relate back to the monopoly rent under the logic of capital (Harvey, 200I). Harvey proposed two forms of monopoly rent, one is to monopolise goods or services produced by land, resources or a location with unique characteristics, and the other is to hoard land or resources instead of putting them into current use, coveting its value in the future. Rehabilitation and exhibition activities have improved the historic city's image. It also advances the appreciation of monopoly rents on the part of local governments and capital enterprises. Sponsoring exhibitions and incubating cultural formats with local characteristics also creates uniqueness or scarcity, enhancing the city's competitiveness. As a result, local governments, capital companies, and third sectors have their respective roles in this cooperative coalition. Historic city regeneration, cultural development, and the monopoly of space and cultural resources are connected in series. From this point of view, groups who have a deep appreciation for the historic city and who participate in exhibition activities are being subsumed under the governance coalition as unique cultural resources. Even if those groups possess a certain amount of freedom, they cannot exert enough impact, and may even be replaced by other groups in the coalition at any time. It is also undeniable that as a result of this process, people or subjects that do not conform with the official understanding and definition of "Seeing people, Seeing things, Seeing life" will be excluded. For example, some shops which have long been operating in local areas and which serve local life but do not have any unique characteristics or do not conform to the historic city's new image, may be included in the category of discouraged facilities in the corresponding form-support policy and thus be forced to either move or close down. In addition, some public spaces that traditionally served local residents are considered to be of less value if they do not have significant utilities. These utilities are attractive to the government and enterprises because they are expected to appreciate and can be monopolised. For example, the pocket park micro-renewal project for Haogou Gully, implemented in the historic city of Quanzhou, was described by the relevant government officials in the following words: "A new street garden will be built on this open space to improve the street environment." However, compared with the design announced in June 2018, the final layout of the pocket park - completed in July 2019 - simplified the design of the rest pavilion and corridor into a few stone benches. It remains to be seen whether this pocket park will really be loved and effectively used by residents. (Figures 7, 8 and 9). As MacLeod (2002) pointed out, any so-called publicness introduced for revival and regeneration is highly selective and systematically discriminating.

Even so, is it possible for publicness to emerge from the interaction between various groups with exhibitions serving as the medium? Influenced by traditional Confucianism, the meaning attributed to the concept of "publicness" in China is not the same as the definition - founded upon democracy and debate - which is prevalent in the West. It is more like a social contract based on consultation and consensus (Rowe, 2005:167), and therefore lacks grassroots power. Due to this kind of collective-contract spirit, the traditional neighbourhood model is often taken up as the ideal type of public space. But when the Recommendation on the Historic Urban Landscape expands the definition of 
historic urban landscape into a more complex structure featuring several layers of urban development, the discussion of public space in the historic city should not be confined to the imagination of traditional neighbourhoods from the past. The traditional publicness in China also needs to face the issue of contemporary urbanity and its new significance under the effects of rapid change.
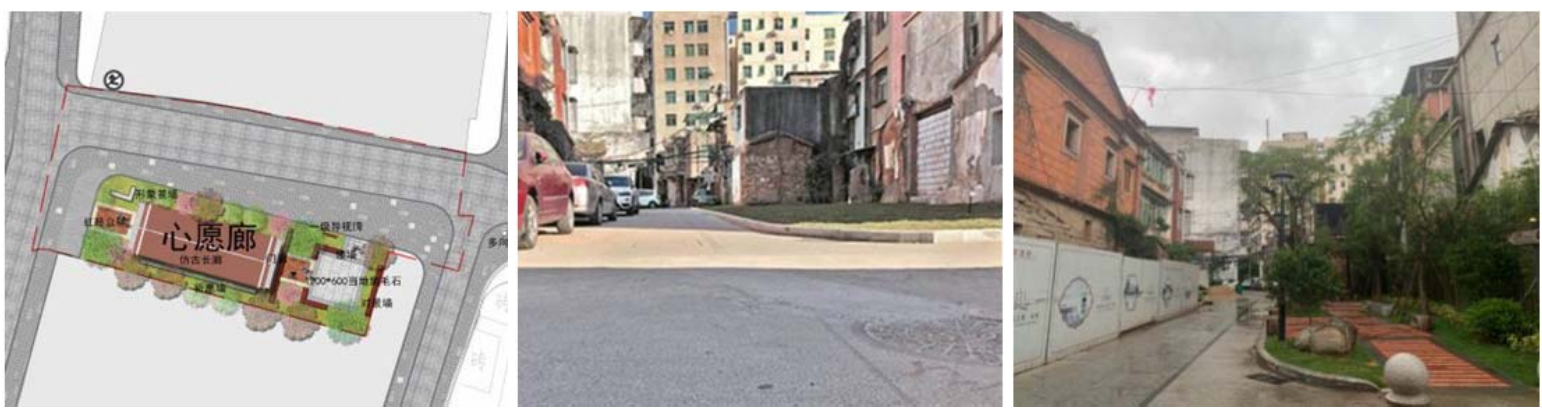

Figure 8-9-10 (from left to right). Pocket Park Design Plan; Reconstruction at the end of 20I8 (Source: Quanzhou Network); Current Status

Returning to the public space put forward by Richard Sennett, his focus is not on democratic participation nor is it on the basis of communicating reason as Habermas would have it, but instead on the open flow of public space and the high tolerance of mixed differences. Event-oriented activities such as "Silent Lubrication", carried out in a wide range of sites in the historic city are not simply general abstract discussions of historic city issues but neither are they deeply immersed within or restricted to particular places. Instead, they intentionally open up dialogues between the outside and the local. Because of the exhibition's irregular, temporary and informal nature, the degree of freedom allowed usually deviates from the existing standards and rules. Such a festival-like carnival provides an opportunity for all parties to make their voices heard. Scholars, artists, students and citizens pour into these activities. Different groups and residents gather together. The collision of various ideas and actions may result in numerous unpredictable consequences and achievements, which play out in daily life. Moreover, these achievements may also generate opportunities to trigger more chain reactions, under the scrutiny of all sectors of society.

To a certain extent, this responds to the definition put forward by Carr et al. (1992: 45) of a successful public space, namely a "social binder" and: "the potential to bring together various groups so that they can learn from each other and become a multiclass, multi-cultural, heterogeneous society with the richest characteristics". It can be said that the exhibition events taking cities as exhibition venues have re-blurred the distinctive public-private boundaries enforced under urban entrepreneurship: some are even in clear opposition to the public space produced by the capital logic. Although located in the historic city, this kind of space differs from the traditional public space which belongs to the past. Such a publicness lies not only in debates, but also in personal entry and reflection, introducing differences and flows, creating connections and actions, and emphasising the activation and cohesion of initiative, thus infusing the 
place with a public lens of contemporary urban characteristics to stimulate more folk practice.

To sum up, the Chinese government is making great efforts to revise the previous model for urban renewal - which is mainly carried out by means of large-scale demolition and reconstruction - and is seeking new ideas and paradigms. Although historic city regeneration is usually highly selective, only benefiting certain special spaces and social groups (Tallon, 2013: 277), compared to the past, real-estate-oriented urban regeneration does still exist throughout the country but it is no longer dominant and continues to weaken gradually. Secondly, the focus of regeneration is returning to balancing public interests and alleviating social problems, and trying to redistribute resources and make effective use of them, which echoes the original intention of urban regeneration in the West. Finally, the participation of the third sector plays a direct role in this process. The third sector can be regarded as an actor, as an active and crucial force operating between local governments and enterprises. The third sector is a vehicle for engaging the public and can use its strength to promote public interests in the regeneration process. Under the trend of a central-government-led concept of "Seeing people, Seeing things, Seeing life" and the gradual revival of the third sector, whether there is an opportunity to balance or even reverse the capital logic of regeneration experience in the historic city is a topic worthy of both long-term observation and discussion.

\section{Reference}

Atkinson, R., \& Moon, G. ( 1994). Urban Policy in Britain: The City, the State and the Market. Macmillan International Higher Education.

Bolton, R. (1989). Figments of the Public: Architecture and Debt. Threshold, 4: 44-49.

Britton, S. (1991). Tourism, Capital, and Place: Towards a Critical Geography of Tourism. Environment and planning D: society and space, 9(4): 45I-478.

Carr, S. (1992). Public Space. Cambridge University Press.

Carter, E. \& Donald, J. (1993). Space and Place: Theories of Identity and Location. Lawrence \& Wishart Ltd.

Chen, L. \& Zhang, W. (20I0). The Change and Reconstruction of Local Culture in Response to Urban Renewal and Globalization: A Case Study of Shichahai Historic District. Progress in geography, 29(6): 649-656.

Dong, G. (2006). A Fifty-year Evolutionary Record of Ancient Capital of Beijing. Nanjing: Southeast University Press.

CLG (2008). Transforming Places; Changing Lives: A Framework for Regeneration. Communities and Local Government, London.

IPF (2009). Urban Regeneration: Opportunities for Property Investment. Investment Property Forum (IPF), London.

Fraser, N. (1990). Rethinking the Public Sphere: A Contribution to the Critique of Actually Existing Democracy. Social text, (25/26): 56-80.

Kung, S. (2006). Social Network Booting, Urban Micro-regeneration Acting. Time Architecture, 2016 (4): 29-33.

Kwok, Y. C. J. (20I I). The Production of Space in East Asian Cities: Urban Cultures of Tokyo, Shanghai and Hong Kong. Taipei: Garden City. 
Habermas, J. (1989). The Structural Transformation of the Public Sphere, trans. Thomas Burger. Cambridge: MIT Press.

Harvey, D. (200I). Spaces of Capital: Towards a Critical Geography. Routledge.

Harvey, D. (2005). Spaces of Neoliberalization: Towards a Theory of Uneven Geographical Development (Vol. 8). Franz Steiner Verlag.

He, S., \& Wu, F. (2009). China's Emerging Neoliberal Urbanism: Perspectives From Urban Dedevelopment. Antipode, 4I(2): 282-304.

Healey, P., Davoudi, S., Tavsanoglu, S., O'Toole, M. and Usher, D. (eds.) (1992). Rebuilding the City: Property-Led Urban Regeneration, London: E \& FN Spon.

Herbert, D. (2000). Towns and Cities. In V. Gardiner and H. Matthews (eds.), The Changing Geography of the United Kingdom (pp. 190-2/2), London: Routledge, 3rd e.

Hidaka, T., \& Tanaka, M. (200I). Japanese Public Space as Defined by Event. In Public Places in Asia Pacific Cities (pp. 107-I 18). Springer Netherlands.

Huang Y. (2004). Houhai Family: Living in the Lost Landscape. In Zhang Z. (eds.), China in 2004 Rising China and the World (Pp. I2I-126). China Citic Press.

Jacobs, J. (1992). The Death and Life of Great American Cities. New York: Vintage.

Kang M. (20I2). Urban Conservation in the Booty Capitalist City. Router: a journal of cultural studies, (I5): 230-24I.

MacLeod, G. (2002). From Urban Entrepreneurialism to a 'Revanchist City'? On the Spatial Injustices of Glasgow's Renaissance. Antipode, 34(3): 602-624.

Sennett, R. (2017). The Fall of Public Man. WW Norton \& Company.

Quanzhou Planning Bureau (2007), Quanzhou Historic City Protection and the Remediation Planning Specification. Quanzhou: Quanzhou Planning Bureau.

Roberts, P. \& Sykes, H. (1999). Urban Regeneration: A Handbook. London: SAGE

Rowe, P. (2005). East Asia Modern: Shaping the Contemporary City. London: Reaktion. 
Shi, Y. (2015). Becoming Citizens: State and Individual in Inner City Renewal and Urban Social Movements. Beijing: Social sciences academic press.

Smith, N. (2002). New Globalism, New Urbanism: Gentrification as Global Urban Strategy. Antipode, 34(3): 427-450.

Su, X., (20I5). Urban Entrepreneurialism and the Commodification of Heritage in China. Urban Studies, 52(15): 2874-2889.

Tallon, A. (20I3). Urban Regeneration in the UK. London: Routledge.

Turok, I. (1992). Property-led Urban Regeneration: Panacea or Placebo? Environment and Planning A, 24: 36I-379.

Wang C., Shen M. \& Lin C. (2009). Politics of Boundary-making in Ethnic Public Spaces: Southeast Asian Landscapes of Consumption in Outer Taipei Metropolitan Area. Taiwan Journal of Southeast Asian Studies, 6(I): 4-48.

Whitehand, J. W. R. and Gu K. (2007). Urban Conservation in China: Historical Development, Current Practice and Morphological Approach. The Town Planning Review, 78(5): 643-670.

Yang, D. (2006). City Monsoon: Cultural Spirit of Beijing and Shanghai. Beijing: New Star Press.

Zhang, J. (20I4). Study on Land Redevelopment and Management of Inner City in Beijing under Perspective of Historic Urban Quarters Protection. Beijing: Capital Normal University Press.

Zhao, Z. (2002). The Characteristics of Chinese Historic Cultural Cities and Their Preservation. City planning review 26(7): 35-38.

Zhao, $\mathrm{H}$. (20I2). The restructuring and preservation of Hutong and courtyards horses in the inner city of Beijing. Doctoral Dissertation. Taipei: National Taiwan University.

Zou, C. (20I5). David Harvey's Geographical Critique of Capitalism. Homeward Publishing.

Zukin, S. (1996). The Cultures of Cities. Wiley-Blackwell.

I64 | The Journal of Public Space, 4(2), 2019 | ISSN 2206-9658

City Space Architecture / UN-Habitat 